\title{
Towards Colorless Distributed Combustion Regime
}

\author{
Ahmed E.E. Khalil and Ashwani K. Gupta* \\ Department of Mechanical Engineering, \\ University of Maryland, College Park, MD 20742, USA
}

\begin{abstract}
Colorless distributed combustion (CDC) is a novel method for efficient and environmentally benign cleaner energy conversion of fossil and biofuels. CDC has been investigated in different configurations and geometries, with support to seek near zero emissions, uniform thermal field, energy savings, low pressure drop, and reduced combustion noise. In this paper, distributed combustion is investigated with focus on the flame-flowfield interaction and the different quantities that affect distributed combustion. The velocity field was obtained using Particle Image Velocimetry (PIV) with focus on mean and fluctuating quantities. The flowfield information helped differentiate between the impact of increasing Reynolds number (through air dilution) and the impact of lowering oxygen concentration (through modelled entrainment). The flowfield information was further processed to give the integral length scale at the flame boundaries. The integral length scale along with the fluctuating velocity is critical to determine turbulence Reynolds number and Damköhler number. Together these numbers identify the combustion regime at which the combustor is operating. This information clearly distinguishes between traditional swirl flames and distributed combustion and helps explain the significant benefits of distributed combustion as it operates in a well-stirred reactor regime. The results revealed that major controllers of the reaction regime are flame thickness and laminar flame speed; both are significantly impacted by lowering oxygen concentration through entrainment of hot reactive species from within the combustor, which is important in distributed combustion. Understanding the controlling factors of CDC is critical for the development and deployment of this novel method for near zero emissions from high intensity combustors and energy savings using fossil and of biofuels for sustainable energy conversion.
\end{abstract}

Keywords: Colorless distributed combustion, Particle image velocimetry (PIV), Integral length scale, Turbulence Reynolds number, Damköhler number, Gas turbine combustion.

* Corresponding author: Distinguished University Professor; Tel.: +1 301405 5276; Fax: +1 301 314 9477; E-mail: akgupta@umd.edu (A. K. Gupta). 


\section{Introduction}

The quest for cleaner energy sources have motivated combustion researchers to develop novel technologies that can deliver high combustion efficiency with favorable environmental performance using available traditional and derived fuels, such as biofuels. To that end, colorless distributed combustion (CDC) offers most promise for near zero emission to conform to the increasingly stringent pollutants emission regulation. The performance of CDC has been the focus of investigations for the last decade over a wide variety of geometries, heat release intensities, and fuels [1-4], with the goals of near zero pollutants emission and overall enhanced performance. Laboratory scale experiments on CDC revealed fuel flexibility for both liquid and gaseous fuels including biofuels $[4,5]$. The use of biofuel without the need to change any of the combustor components as a "drop-in" fuel is critical to increase the deployment of biofuels in current and future high intensity stationary gas turbine engines. Laboratory scale experiments have revealed that different biofuels can be used directly as a "drop-in" fuel with no change to the fuel injectors/combustor geometry. These experiments have also shown that biofuels (Butyl Nonanoate and Hydrogenated Renewable Jet Fuel) can have lower pollutants emission compared to fossil liquid fuels (kerosene, JP-8) [5]. The results on much reduced emission is an addition to the benefits of biofuels in reducing the life cycle greenhouse gas emissions by some $60-80 \%$ (Switchgrass Fischer-Tropsch fuel [6] and Camelina hydrogenated renewable jet fuel [6, 7]). Other researchers have also focused on tackling these issues concerning combustion and emissions with more focus on furnaces than gas turbine applications [8-12].

The CDC technology shares some of the basic principles on which high temperature air combustion (HiTAC) was built [13]. HiTAC has demonstrated ultra-low emissions, uniform thermal field, and significant energy gains for near atmospheric pressure furnace applications. In 
HiTAC, low oxygen concentration air, preheated to high temperatures along with reactive gas species are used for combustion. This method resulted in combustion gases temperature that is some $50-100^{\circ} \mathrm{C}$ higher than that of the preheated low oxygen concentration fuel-air mixture just prior to ignition. The low oxygen concentration in the reactants ( 2 5\% by volume) is achieved through the internal/external entrainment of combustion gases, which also increases the air temperature [13].

On the other hand, in CDC, decrease in oxygen concentration and increase in temperature of the fresh mixture stream is achieved through internal entrainment of hot reactive species from within the combustor. This entrainment and the subsequent adequate mixing prior to ignition are critical components in distributed combustion that results in volume-distributed reaction over the entire volume of the combustor. The volume distributed combustion is much different than normal combustion that possess a thin concentrated reaction zone characterized by high reaction rates and presence of local hot spots. It is noteworthy that the same amount of fuel is consumed but with a lower temperature rise in the combustor. This low reaction rate is achieved through increased dilution with hot reactive species that also lowers the oxygen concentration in the reactants, and simultaneously increase temperature of the reactants. The term colorless stems from the lack of visible emission from the flame under normal conditions.

The distributed combustion regime avoids the formation of thin reaction zone and the hot spot zones in the flame. This significantly helps in mitigating thermal $\mathrm{NO}_{\mathrm{x}}$ formation and emission from the Zeldovich thermal mechanism [14]. The overall temperature of the flame is low so that there is less or no need to dilute the hot gases before introducing them to the turbine. This reduces power requirements of the gas turbine's compressor to directly enhance the gas turbine efficiency and simultaneously enhance both combustor and turbine lifetime. 
The enhanced thermal field uniformity can also allow the combustor to fire at higher average temperature since there will be less temperature deviation from the average temperature and lower risk of burnout along with minimal or none air cooling requirements for turbine blades. Mitigation of the cooling air requirements will help increase the amount of gases available for work through the turbine or use of smaller size compressor. Alternatively, the increased work can be used to power the carbon capture and storage equipment. The deployment of carbon capture and storage technologies is critical for continued use of hydrocarbon fuels while minimizing the resultant carbon footprint and complying with the envisioned increase in pollutants emissions regulations. These potential benefits of deploying CDC add to the importance of investigating CDC in more details for wider deployment.

There is plenty of literature investigating distributed combustion in terms of pollutants emission demonstration [1-5], requirements to achieve distributed combustion for methane fuel [15] and other fuels as well [16], that offer much insight on the role of entrainment. However, critical questions still remain concerning the nature of distributed combustion and its regime with focus on flame interaction with the turbulence field. In a previous investigation, the velocity flowfield under swirl flames and distributed combustion conditions was investigated with focus to extract the difference in flowfield under the two conditions of swirl assisted combustion and distributed combustion. The information obtained from PIV was coupled with OH-PLIF to qualitatively outline the reaction behavior. It was concluded that under distributed combustion, the $\mathrm{OH}$ zone resided farther away from the entry jet and high turbulence region. This is much different than that found in swirl flame as previously shown by the authors [17]. In this paper, the interaction between flame characteristics and flow characteristics are compared with focus on turbulent quantities (integral length scale and turbulent Reynolds number) and reaction time 
scale quantities (flame speed and thickness), which have not performed before. This helps to identify and establish combustion regime for colorless distributed combustion.

Flame regimes are characterized by the reaction time scale and flow time scale. The distributed combustion regime is characterized by low Damköhler number, where the integral length scale is equal to or less than the flame thickness such that the combustion behavior is dictated by turbulent behavior rather than the molecular transport. High turbulence insures rapid mixing between entrained gases with the fresh stream, while high injection velocity prevents flame anchoring. Thus, the distributed combustion regime is different than traditional reaction sheets or flamelets in eddies regime. Figure 1 shows the different regimes on adapted Borghi diagram [18-20], outlining the relative location of colorless distributed combustion along with the HiTAC and other flames.

Several researchers have combined different diagnostics to obtain the velocity field, and flame location and thickness for different flame configurations [21-28], resulting in useful insights for the different cases investigated in their respective investigations. However, limited data is available for distributed combustion simulating gas turbine conditions. A focus of this paper is to fill this gap.

\section{Experimental Facility}

\subsection{Experimental Setup}

The experiments were performed using a swirl burner under different configurations. Details of the swirl burner can be found elsewhere [29]. The experimental set-up, diagnostics, and flow control system used for the different gases along with their accuracies are given elsewhere [17].

The Swirl number (S) for the swirler used can be calculated using the equation $S=2 / 3[(1-$ $\left.\left.\left(d_{h} / d\right)^{\wedge} 3\right) /\left(1-\left(d_{h} / d\right)^{\wedge} 2\right)\right] \tan \Phi$, where $d$ is the swirler diameter, $d_{h}$ is the swirl hub diameter, $\Phi$ is the 
swirl angle. For the shown configuration, with $\mathrm{d}_{\mathrm{h}} / \mathrm{d}=0.5$, and $\Phi=45$, the swirl number was estimated to be $S=0.77$.

\subsection{Laser Diagnostics}

Particle image velocimetry (PIV) system was used to obtain the flowfield. Further details about the setup and initial processing are given elsewhere [17]. The number of image pairs were determined based on the point were further increase in the number of pairs did not yield significant change in the measured quantities $(<5 \%)$ as shown in Fig. 2. Based on this, the

minimum number of pairs was 300. The PIVLab output was further processed in Matlab to obtain mean and fluctuating velocities and other statistical quantities.

$\mathrm{OH}$ radicals were excited using a dye laser system with ultra violet tracking (UVT) targeting the $\mathrm{Q}_{1}(6)$ line with the wavelength chosen based on the work of Dieke et al. using LIFBASE software [31, 32]. Details of the PLIF system are available elsewhere [17].

\section{Experimental Conditions}

The experimental investigations reported here were focused on obtaining the velocity field and turbulence quantities, as well as $\mathrm{OH}^{*}$ distribution for all the cases examined. The first examined case focused on confined swirl burner as a baseline case. A mixture of nitrogen and carbon dioxide was added to simulate entrained gases from within the flame with different amounts, lowering the oxygen concentration of the ready to ignite mixture (cases 2-4). The amounts of $\mathrm{N}_{2}-\mathrm{CO}_{2}$ mixture and their impact on emissions have previously been examined [15]. Conditions demonstrated distributed combustion were compared to this baseline case with focus on turbulence and flame interaction (cases 3 and 4); case two represented transition between regular swirl and distributed combustion. The fifth case was designed to result in the same 
Reynolds number as cases 3 and 4 but with excess air rather than diluents. This fifth case was studied to substantiate the impact of oxygen reduction as opposed to dilution and increased flow velocities. The gases were fed to the combustor at room temperature. The $\mathrm{N}_{2} / \mathrm{CO}_{2}$ mixture, simulating entrained gases from within the flame, has been examined at higher temperature where the overall behavior on reaction distribution and emission reduction was found to be similar to that of the non-preheated case [15]. However, in this investigation preheating was not used as it severely affected the seeding quality and distribution as the seeding particles were fed through the $\mathrm{N}_{2} / \mathrm{CO}_{2}$ mixture for cases 2-4. The seeding particles can be fed through the air line, as in case 1 and 5, however, following that approach for cases 2-4 led to reduced number of usable frames for PIV diagnostics, as it took longer time for the flame to reach the desired experimental conditions. This limited the time available for data acquisition prior to seed deposition on the quartz windows. Table 1 summarizes the operating conditions for each of the experimental cases investigated herein while figure 3 shows the flame images for these cases with a filter to minimize the impact of the seeding. It is noteworthy that the change did not only occur to the flame shape as seen here and in previous publication [33], but also on the pollutants emission, thermal field uniformity, and local equivalence ratio distribution as shown in previous investigations $[15,33,34]$. The fuel flow rate was kept constant for all the experiments to result in a constant thermal load.

\section{Results and Discussion}

\subsection{Velocity flow field}

The first experimental step was to obtain the flowfield under reacting flow conditions for cases 1-5. Figure 4 shows the velocity vectors for cases 1-4 along with the mean velocity values, where the white band (zero velocity) marks the recirculation zone boundary. As the diluents 
amount increased, the velocity magnitude increases in the entry jet (positive) as well as the central recirculation zone (negative). It is noteworthy that the investigation window covered up to $2.7 \mathrm{~cm}$ of radius while the full radius of the confinement was $3.9 \mathrm{~cm}$. This area was not included due to the high noise from quartz reflections and particle deposition. In addition, the two vertical white bands mark high noise area that was masked to eliminate erroneous vectors.

Figure 5 shows the stream-trace lines, outlining the movement of the flow for the different cases. As the oxygen concentration was decreased (through dilution), the angle of the streamlines in the recirculation zone become more steep, with the streamlines being more vertical as one progressed from case 1 to case 4, indicating a stronger recirculation. One can conjecture that this increase in recirculation and the resultant change in reaction shape and behavior (see Fig. 3, as well as previous publications examining the behavior of the discussed case in terms of emission, $\mathrm{OH}^{*}$ distribution, thermal field, and local equivalence ratio $\left.[15,33,34]\right)$ is a result of increased flow rates (Reynolds number) with no or minimal involvement from the change in oxygen concentration.

To examine this effect, cases 3 and 4 are compared to case 5, which exhibits the similar Reynolds number, however, the main difference is the amount of oxygen concentration.

Figure 6 shows a comparison between cases 3-5. This comparison clearly indicates the impact of oxygen concentration. Though the three cases have similar Reynolds number (varying by less than $6 \%$ ), the flowfield is significantly different. The low oxygen concentration cases (case $3 \&$ 4) exhibited a closed recirculation zone (where the recirculation zone widens as one moves downstream then gets thinner). This was not seen in case 5. In addition, case 5 exhibited lower recirculation as seen from the lower negative velocities at the center of the recirculation zone, as well as the streamlines traces being less steep in the normal oxygen concentration case (case 5) 
as compared to the cases with low oxygen concentration (cases $3 \& 4$ ). These results conclude that lowering oxygen concentration has a significant effect on the flowfield as opposed to increasing Reynolds number, outlining the flame-flow interaction. Moreover, the adiabatic flame temperature for these scenarios only differ by $2.5 \%$ from case 5 (1693K, $1627.8 \mathrm{~K}$, and $1665.5 \mathrm{~K}$ for cases 3,4 , and 5 respectively), limiting the impact of thermal expansion. This supports the previous studies that showed that lowering oxygen concentration, not increasing the velocity, helps to achieve distributed combustion and thermal field uniformity [17, 33]. In addition, this significantly differentiates the phenomenon investigated here (distributed combustion) from the so-called M-shape flame demonstrated in some swirl designs as that on its own did not result in distributed combustion while cases $3 \& 4$ did. Arndt et al. examined a swirl combustor where, under certain conditions, the flame transitioned between V-shape (seen here without dilution, $\mathrm{O}_{2}=21 \%$ ) and $\mathrm{M}$-shape unpredictably [27]. However, the flame shape demonstrated herein (under distributed combustion cases $3 \& 4$ ) is extremely stable and did not move back to traditional swirl flame unless the oxygen concentration was significantly increased (amount of $\mathrm{N}_{2} / \mathrm{CO}_{2}$ mixture significantly decreased). Oberleithner et al. also demonstrated an M-shaped flame under low equivalence ratio and increased heat loads [28]. However, our previous investigations showed that decreasing the equivalence ratio or increasing the heat load did not result in a flame shape change, confirming that the flame shown here is distinctively different $[15,17]$. To further investigate the flame-flow interaction, turbulence quantities were also characterized.

\subsection{Turbulence Characteristics}

The flowfield velocities were further analyzed to obtain the fluctuating velocity values (root mean square velocity). Figure 7 shows the velocity fluctuations (in $\mathrm{m} / \mathrm{s}$ ) for cases 1-5. 
As the amounts of diluents were increased from the baseline case until distributed combustion was achieved, the velocity fluctuations remained similar in the entry region (V-shaped) corresponding to the high velocity region. On the other hand, the fluctuation velocities in the core decreased significantly with transition to distributed combustion condition (cases $3 \& 4$ ). This was not caused by the increased velocity but rather because of change in flame behavior. This is confirmed through comparing cases 3-5 in Fig 7. The three of them have the same Reynolds number (within 6\%), however, case 5 demonstrates much higher velocity fluctuation in the entry jet (the v-shaped higher velocity region) as well as higher fluctuations in the central recirculation zone as compared to the distributed combustion (cases $3 \& 4$ ).

To calculate turbulence Reynolds number, the integral length scale needs to be quantified in addition to the velocity fluctuation, which is shown in Fig 7. To obtain the integral length scale, the velocity fluctuations were analyzed using two-point correlations [35, 36], where the integration of the correlation coefficient results in the integral length scale $[37,38]$.

$\rho_{\mathrm{ii}}=\left[\mathrm{v}\left(\mathrm{x}_{\mathrm{o}}, \mathrm{t}\right) * \mathrm{v}\left(\mathrm{x}_{\mathrm{o}}+\mathrm{r}, \mathrm{t}\right)\right] /\left(\left\langle\mathrm{v}\left(\mathrm{x}_{\mathrm{o}}\right)\right\rangle *\left\langle\mathrm{v}\left(\mathrm{x}_{\mathrm{o}}\right)\right\rangle\right)$

$\lambda=\int_{0}^{\infty} \rho_{i i} d r$

In these equations, $\rho_{\mathrm{ii}}$ represents the correlation coefficient, $\mathrm{v}\left(\mathrm{x}_{\mathrm{o}}, \mathrm{t}\right)$ represents the velocity at a certain position $\mathrm{x}_{0}$ and time $\mathrm{t}, \mathrm{v}\left(\mathrm{x}_{\mathrm{o}}+\mathrm{r}, \mathrm{t}\right)$ represents the velocity at a certain position $\left(\mathrm{x}_{0}+\mathrm{r}\right)$ and time $\mathrm{t},\left\langle\mathrm{v}\left(\mathrm{x}_{\mathrm{o}}\right)\right\rangle$ represents the average velocity over the all the frames at this position. The square brackets represents ensemble average of the instantaneous velocity fluctuation multiplication. Figure 8 gives a sample of the correlation coefficient value with distance.

Using the above equations, along with knowledge of velocity fluctuations, one can calculate the turbulent Reynolds number for various locations. However, the locations of interest are those 
at the reaction zone boundaries and in the reaction zone. To establish this, the reaction zone needs to be identified.

\subsection{Reaction Zone Quantities}

To outline the reaction zone, OH-PLIF have been performed on the different cases outlining the reaction zone location. $\mathrm{OH}-\mathrm{PLIF}$ was chosen over $\mathrm{OH}^{*}$ chemiluminescence as $\mathrm{OH}-\mathrm{PLIF}$ gives $\mathrm{OH}$ signal in the laser sheet thickness only, while $\mathrm{OH}^{*}$ chemiluminescence provides a line of sight data showing all the excited $\mathrm{OH}$ in the flame at that temperature. Though one can use mathematical techniques to obtain a representation of the radial distribution of $\mathrm{OH}$, i.e. Abel conversion, however, this did not yield satisfactory results under distributed combustion conditions.

Figure 9 shows the OH-PLIF signal (activated through the $\mathrm{Q}_{1}(6)$ line) for case 1,3 and 5 for illustration. To outline the flame boundaries, an edge detection algorithm was used based on the work of Canny [39]. The white lines represent this edge. The data presented in this figure represented the average of the images obtained in each case to result in a general location where the flame boundary sits. Averaging was performed as PLIF and PIV data were not obtained simultaneously, preventing instantaneous comparisons of both fields. It is noteworthy that cases 1 and 5 presented a $\mathrm{V}$-shape flame, which was not demonstrated for case 3, outlining the difference between both flames.

From the detected flame boundary, one can calculate the turbulence Reynolds number at these positions. However, if one were to use Borghi diagram for flame classification, Damköhler number needs to be characterized. Damköhler number is given by:

$$
\mathrm{Da}=\mathrm{t}_{\mathrm{f}} / \mathrm{t}_{\mathrm{c}}
$$


where $t_{f}$ is the flow time scale, $t_{c}$ is the chemical time scale. Both of these time scales can be given by

$$
\begin{aligned}
& t_{\mathrm{f}}=\lambda / V_{\mathrm{rms}} \\
& \mathrm{t}_{\mathrm{c}}=\delta_{\mathrm{f}} / \mathrm{u}_{\mathrm{f}}
\end{aligned}
$$

where $\lambda$ is the integral length scale, $V_{\text {rms }}$ is the velocity fluctuation, $\delta_{\mathrm{f}}$ is the flame thickness, and $\mathrm{u}_{\mathrm{f}}$ is the flame speed.

In the context of this work, for Borghi diagram calculations, laminar flame speed was used following the definitions of Peters [40]. To calculate the flame thickness, the following equation was used

$$
\delta_{\mathrm{f}}=2 \mathrm{k} /\left(\rho_{\mathrm{u}} * \mathrm{C}_{\mathrm{p}} * \mathrm{u}_{\mathrm{f}}\right)
$$

where, $\mathrm{k}$ is the thermal conductivity of the mixture, $\rho_{\mathrm{u}}$ is the unburnt gases density, $\mathrm{C}_{\mathrm{p}}$ is the specific heat capacity [41]. These quantities can be determined knowing the temperature at the desired location. The thermal field of this burner under the cases investigated here has been previously characterized [33], and the temperature values obtained were used herein for this calculation.

The remaining quantity for these calculations was the laminar flame speed. The flame speed for the different conditions examined herein was calculated using CHEMKIN-PRO flame speed library [42] using the GRI 3.0 mechanism [43]. These calculated values agreed favorably with the available literature on flame speed using nitrogen and carbon dioxide dilution $[44,45]$. Table 2 shows the calculated flame speed and thickness for the cases examined. It is noteworthy that the velocities and thicknesses were calculated based on the inlet conditions, which may vary from the actual case due to internal recirculation and mixing, however, it was reasonable to 
assume that these velocities/thicknesses will scale equally compared to each other, providing useful input for these calculations.

Multiple points across the reaction zone boundary were selected for Reynolds number and Damköhler number calculations. These calculations were performed for case 1,3 , 4, and 5 . These points are plotted on a Borghi diagram (Reynolds- Damköhler number plane) in Fig. 10 showing the line separating flamelets in eddies regime and distributed regime.

The average of each of the cases were calculated and presented in Fig. 11. The plotted data showed clearly that upon reduction of oxygen concentration, distributed reaction was established in the combustor. On the other hand, operating the burner with no dilution resulted in a flame that lies in the flamelets in eddies regime. Air dilution, lowering the equivalence ratio and increasing Reynolds number, demonstrated lower Damköhler number, however, the reaction was still in flamelets in eddies regime. The Damköhler number was only significantly reduced upon lowering the oxygen concentration, to achieve distributed combustion, where the integral length scale was less than the flame thickness, indicating significant impact of the turbulence on mixing.

Further insights can be obtained if the data was plotted in a $\lambda / \delta_{\mathrm{f}}-\mathrm{V}_{\mathrm{rms}} / \mathrm{u}_{\mathrm{f}}$ plane, see Fig. 12. This plot shows that the major contributor was the integral length scale along with the flame thickness. For the cases discussed, the turbulence Reynolds number varied around 100, while Damköhler number varied by two orders of magnitude between case 1 and case 4 . If one were to look on the integral length scale to flame thickness, this ratio varied by an order of magnitude, while the velocity ratio varied between 10 and 50 .

For all the cases (and different points examined here), the integral length scale varied by $21 \%$ (from $1.14 \mathrm{~mm}$ for case 1 to $0.9 \mathrm{~mm}$ for case 4 ), while the fluctuating velocity varied by $26 \%$ 
(from $4.32 \mathrm{~m} / \mathrm{s}$ for case 5 to $3.2 \mathrm{~m} / \mathrm{s}$ for case 3). On the other hand, the laminar flame thickness varied by an order of magnitude (from $0.49 \mathrm{~mm}$ case 1 to $2.8 \mathrm{~mm}$ case 4 ), as well as the laminar flame speed (from $0.346 \mathrm{~m} / \mathrm{s}$ case 1 to $0.0595 \mathrm{~m} / \mathrm{s}$ for case 4 ). Both of the latter quantities are function of the constituents, where flame thickness is significantly increased while the laminar flame speed significantly decreased by lowering the oxygen concentration. These attributes help in establishing the distributed combustion regime, as demonstrated here.

\section{Conclusions}

Colorless distributed combustion was investigated in a swirl burner with focus on flame-flow interaction under relevant gas turbine conditions. Velocity flow field data showed that lowering oxygen concentration through diluents for achieving distributed combustion is essentially different as compared to air dilution (lowering equivalence ratio). Though both had the same Reynolds number, the recirculation zone strength was much different, as well the flow field turbulence. Distributed combustion demonstrated higher recirculation and lower fluctuating velocity in the reaction zone as compared to that of lower equivalence ratio case.

The reaction zone was established using OH-PLIF with focus on identifying the reaction boundary to calculate turbulence Reynolds number and Damköhler r number at these boundaries. These calculations revealed that upon achieving distributed combustion, the reaction occurs in a distributed regime that resembles a well-stirred reactor, characterized by low Damköhler number. Further analysis revealed that the major controllers are the flame thickness and laminar flame speed. Lowering oxygen concentration, which is the essence of colorless distributed combustion, results in a much lower flame speed and thicker flame. If the integral length scale is small enough, the reaction occurs in the distributed regime as demonstrated here. 
Understanding the controlling factors to achieve colorless distributed combustion, as provided herein, is key to achieve near zero emissions and enhance performance using traditional and biofuels with minimal or mitigated carbon footprint for sustainable energy conversion.

\section{Acknowledgments}

This research was supported by ONR and is gratefully acknowledged. Access to CHEMKINPRO was provided by Reaction Design/ANSYS and is gratefully acknowledged.

\section{References}

[1] Arghode VK, and Gupta AK. Effect of Flowfield for Colorless Distributed Combustion (CDC) for Gas Turbine Combustion. J. Applied Energy, 2010;78:1631-40.

[2] Khalil AEE, and Gupta AK. Swirling Distributed Combustion For Clean Energy Conversion In Gas Turbine Applications. J. Applied Energy, 2011;88:3685-93.

[3] Khalil AEE, Gupta AK, Bryden MK, Lee SC. Mixture Preparation Effects on Distributed Combustion for Gas Turbine Applications. J. Energy Resour. Technol., 2012;134(3):032201.

[4] Khalil AEE, and Gupta, AK. Fuel Flexible Distributed Combustion with Swirl for Gas Turbine Applications. J. Applied Energy, 2013;109:327-334.

[5] Khalil AEE, and Gupta, AK. Clean Combustion in Gas Turbine Engines using Butyl Nonanoate Biofuel. Fuel, 2014;116:522-528.

[6] Carter NA, Stratton RW, Bredehoeft, MK, and Hileman, JI. Energy and Environmental Viability of Select Alternative Jet Fuel Pathways. 47th AIAA/ASME/SAE/ASEE Joint Propulsion Conference, San Diego, CA, 2011 
[7] Shonnard DR, Williams L, and Kalnes TN. Camelina-Derived Jet Fuel and Diesel: Sustainable Advanced Biofuels. Environmental Progress \& Sustainable Energy, 2010;29(3):382392.

[8] Wunning JA and Wunning JG. Flameless Oxidation to Reduce Thermal NO Formation. Progr. In Energy and Combustion Science, 1997;23:81-94.

[9] Lammel O, Schutz H, Schmitz G, Luckerath R, Stohr M, Noll B, Aigner M, Hase M, Krebs W. FLOX Combustion at High Power Density and High Flame Temperature. J. Eng. Gas Turb. Power, 2010;132(12):121503

[10] Cavaliere A, de Joannon, M. MILD Combustion, Progress in Energy and Combustion Science, 2004;30(4):329-366

[11] Weber R, Smart JP, and Vd Kamp W. On the (MILD) Combustion of Gaseous, Liquid, and Solid Fuels in High Temperature Preheated Air. Proc. Combust. Inst, 2005;30:2623-2629.

[12] Szego, G.G., Dally, B.B., Nathan, G.J., Operational Characteristics of a Parallel Jet MILD Combustion Burner System. Combustion and Flame, 2009;156(2):429-438

[13] Tsuji H, Gupta AK, Hasegawa T, Katsuki M, Kishimoto K, Morita M. High temperature air combustion: from energy conservation to pollution reduction. Boca Raton: CRC Press.;2003

[14] Correa SM. A Review of NOx Formation under Gas-Turbine Combustion Conditions. Combustion Science and Technology, 1992;87:329-62.

[15] Khalil AEE, and Gupta AK. Impact of Internal Entrainment on High Intensity Distributed Combustion. J. Applied Energy, 2015;156:241-250.

[16] Khalil AEE, and Gupta AK. Fuel Property Effects on Distributed Combustion, Fuel, 2016;171:116-124 
[17] Khalil AEE, and Gupta AK. On the Flame-Flow interaction under Distributed Combustion Conditions, Fuel, 2016;182:17-26.

[18] Williams, FA. Turbulent Combustion. The Mathematics of Combustion (ed. J. Buckmaster), 1985:ch3: 97:131

[19] Abdel-Gayed, RG. and Bradley D. Combustion Regimes and the Straining of Turbulent Premixed Flames. Combustion and Flame, 1989;76:213-218

[20] Peters, N. The Turbulent Burning Velocity for Large-Scale and Small-Scale Turbulence. J. Fluid Mech., 1999;384:107-132

[21] Weigand P, Meier W, Duan XR, Stricker W, and Aigner M. Investigations of Swirl Flames in a Gas Turbine Model Combustor. I. Flow Field, Structures, Temperature, and Species Distributions. Combustion and Flame, 2006;144:205-224.

[22] Stohr M, Sadanandan R, and Meier W. Experimental Study of Unsteady Flame Structures of an Oscillating Swirl Flame in a Gas Turbine Model Combustor. Proc. Combust. Inst., 2009;32:2925-2932.

[23] Stopper U, Aigner M, Ax H, Meier W, Sadanandan R, Stohr M, and Bonaldo A. PIV, 2D-LIF and 1D-Raman Measurements of Flow Field, Composition and Temperature in Premixed Gas Turbine Flames. Exp. Thermal and Fluid Sci., 2010;34:396-403.

[24] Sadanandan R, Stohr M, and Meier W. Simultaneous OH-PLIF and PIV Measurements in a Gas Turbine Model Combustor. Appl. Phys B., 2008;90:609-618.

[25] Han D, and Mungal MG. Simultaneous Measurement of Velocity and CH Layer Distribution in Turbulent Non-Premixed Flames. Proc. Combust. Inst., 2000;28:261-267. 
[26] Kothnur S, Tsurikov MS, Clemens NT, Donbar JM, and Carter CD. Planar Imaging of $\mathrm{CH}, \mathrm{OH}$, and Velocity in Turbulent Non-Premixed Jet Flames. Proc. Combust. Inst., 2002;29:1921-1927.

[27] Arndt CM, Steinberg AM, Boxx IG, Meier W, Carter CD, and Aigner M. Flow-Field and Flame Dynamics of a Gas Turbine Model Combustor During Transition Between ThermoAcoustically Stable und Unstable States. Proc. ASME Turbo Expo, 2010, GT2010-22830

[28] Oberleithner K, Stöhr M, Im SH, Arndt CM, and Steinberg AM. Formation and FlameInduced Suppression of the Precessing Vortex Core in a Swirl Combustor: Experiments and Linear Stability Analysis. Combustion and Flame, 2015;162:3100-3114

[29] Kim HS, Arghode VK, Linck MB, Gupta AK. Hydrogen Addition Effects in a Confined Swirl-Stabilized Methane-Air Flame. Int'1 J. Hydrogen Energy, 2009;34(2):1054-1062.

[30] Thielicke W, and Stamhuis EJ. PIVlab - Time-Resolved Digital Particle Image Velocimetry Tool for MATLAB (version: 1.4). http://dx.doi.org/10.6084/m9.figshare.1092508

[31] Dieke CH, and Crosswhite HM. The Ultraviolet Bands of OH. J. Quant. Spectrosc. Radiat. Transfer, 1962;2(2):97-199.

[32] Luque J, and Crosley DR. LIFBASE: Database and spectral simulation (version 1.5). SRI International Report MP 99-009, 1999.

[33] Khalil AEE, and Gupta AK. Thermal Field Investigation under Distributed Combustion Conditions. J. Applied Energy, 2015;160:477-488

[34] Khalil AEE, and Gupta AK. Internal Entrainment Effects on High Intensity Distributed Combustion Using Non-Intrusive Diagnostics. J. Applied Energy, 2015;160:467-476

[35] Davidson, PA. Turbulence, An Introduction for Scientists and Engineers. Oxford University Press, Oxford, UK, 2004. 
[36] Ewing, D., George, WK., Rogers, MM., and Moser, RD. Two-Point Similarity in Temporally Evolving Plane Wakes. J. Fluid Mech., 2007;577:287-307.

[37] O’Neill, P.L., Nicolaides, D., Honnery, D., and Soria, J. Autocorrelation Functions and the Determination of Integral Length with Reference to Experimental and Numerical Data. 15th Australasian Fluid Mechanics Conference, The University of Sydney, Sydney, Australia, 13-17 December 2004

[38] Pandaa, PP., Roa, M., Slabaugh CD., Peltier, S., Carter CD., Laster, WR., and Lucht, RP. High-Repetition-Rate Planar Measurements in the Wake of a Reacting Jet Injected into a Swirling Vitiated Crossflow. Combustion and Flame, 2016;163:241-257

[39] Canny, J. A Computational Approach to Edge Detection. IEEE Transactions on Pattern Analysis and Machine Intelligence, 1986;PAMI-8(6):679-698

[40] Peters, N. Laminar Flamelet Concepts in Turbulent Combustion. $21^{\text {st }}$ Symposium (Intl) on Combustion, The Combustion Institute 1986;21:1231-1250

[41] Turns, SR. An Introduction to Combustion: Concepts and Applications. McGraw-Hill, Boston, 2006.

[42] CHEMKIN-PRO 15131, Reaction Design: San Diego, 2013

[43] Smith GP., Golden DM., Frenklach M. Moriarty NW., Eiteneer B., Goldenberg M., Bowman CT., Hanson RK., Song S., Gardiner WC., Lissianski VV. and Qin Z. GRI 3.0 Mechanism, http://www.me.berkeley.edu/gri_mech/.

[44] Stone, R., Clarke, A., and Beckwith, P. Correlations for the Laminar-Burning Velocity of Methane/Diluent/Air Mixtures Obtained in Free-Fall Experiments. Combustion and Flame, 1998;114(3-4):546-555 
[45] Galmiche, B., Halter, F., Foucher, F., and Dagut, P. Effects of Dilution on Laminar Burning Velocity of Premixed Methane/Air Flames. Energy \& Fuels, 2011;25:948-954 
Table 1. Experimental parameters

\begin{tabular}{|c|c|c|c|c|c|c|c|}
\hline & \multirow{2}{*}{$\begin{array}{c}\text { Equivalence } \\
\text { Ratio }\end{array}$} & \multirow{2}{*}{$\begin{array}{l}\text { Reynolds' } \\
\text { Number }\end{array}$} & \multicolumn{2}{|c|}{ Flowrates [1/min] } & \multicolumn{2}{|c|}{ Diluents [1/min] } & \multirow[t]{2}{*}{ Oxygen Conc. [\%] } \\
\hline & & & Air & $\mathrm{CH}_{4}$ & $\mathbf{N}_{2}$ & $\mathrm{CO}_{2}$ & \\
\hline 1 & 0.9 & $\sim 4450$ & $63.9 \pm 0.9$ & $6 \pm 0.1$ & - & - & $21 \%$ \\
\hline 2 & 0.9 & $\sim 5640$ & $63.9 \pm 0.9$ & $6 \pm 0.1$ & $\mathbf{1 5} \pm 0.23$ & $\mathbf{1 . 6 7} \pm 0.03$ & $16.65 \%$ \\
\hline 3 & 0.9 & $\sim 6430$ & $63.9 \pm 0.9$ & $6 \pm 0.1$ & $\mathbf{2 5} \pm 0.38$ & $\mathbf{2 . 7 8} \pm 0.04$ & $14.64 \%$ \\
\hline 4 & 0.9 & $\sim 6800$ & $63.9 \pm 0.9$ & $6 \pm 0.1$ & $\mathbf{3 0} \pm 0.45$ & $\mathbf{3 . 3 3} \pm 0.05$ & $13.8 \%$ \\
\hline 5 & 0.6 & $\sim 6450$ & $95.2 \pm 1.4$ & $6 \pm 0.1$ & - & - & $21 \%$ \\
\hline
\end{tabular}


Table 2. Calculated values for laminar flame speed and thickness

\begin{tabular}{|c|c|c|c|c|c|}
\hline Case & $\begin{array}{c}\text { Equivalence } \\
\text { Ratio }\end{array}$ & $\begin{array}{c}\text { Reynolds } \\
\text { Number }\end{array}$ & $\begin{array}{c}\text { Oxygen Conc. } \\
{[\%]}\end{array}$ & $\begin{array}{c}\text { Laminar Flame } \\
\text { Speed }[\mathrm{m} / \mathrm{s}]\end{array}$ & $\begin{array}{c}\text { Flame Thickness } \\
{[\mathrm{mm}]}\end{array}$ \\
\hline 1 & $\mathbf{0 . 9}$ & $\sim 4450$ & $21 \%$ & 0.346 & 0.491 \\
\hline 3 & $\mathbf{0 . 9}$ & $\sim 6430$ & $14.64 \%$ & 0.0808 & 2.06 \\
\hline 4 & 0.9 & $\sim 6800$ & $13.8 \%$ & 0.0595 & $\mathbf{2 . 8 1 3}$ \\
\hline 5 & $\mathbf{0 . 6}$ & $\sim 6450$ & $21 \%$ & $\mathbf{0 . 1 1 6}$ & 1.45 \\
\hline
\end{tabular}




\section{Figure Captions}

Figure 1. Combustion regimes with respect to $\mathrm{Da}$ and $\mathrm{Re}$ `.

Figure 2. Percentage change in mean and fluctuating velocities vs. number of image pairs.

Figure 3. Flame images of the cases investigated. Red filter is used to remove the impact of seeding

5 particles.

Figure 4. Velocity flow field for cases 1-4 with focus on velocity vectors. [For illustration, recirculation zone is outlined by white band]

Figure 5. Velocity flow field for cases 1-4 with focus on streamlines trace. [For illustration, recirculation zone is outlined by white band]

Figure 6. Velocity flow field for cases 3-5 with focus on velocity vectors (top) and streamline traces

(bottom). [For illustration, recirculation zone is outlined by white band]

Figure 7. Velocity fluctuations $\left(\mathrm{V}_{\mathrm{rms}}\right)$ in $\mathrm{m} / \mathrm{s}$ for the different cases examined.

Figure 8. Sample data for correlation coefficient vs. distance.

Figure 9. OH-PLIF signal with flame boundary detection.

15 Figure 10. Combustion regimes for cases $1,3,4$, and 5 at the different flame boundary locations examined.

Figure 11. Combustion Regimes for cases 1, 3, 4, and 5.

Figure 12. Combustion Regimes for cases 1, 3, 4, and 5.

Table Captions

Table 1. Experimental parameters

Table 2. Calculated values for laminar flame speed and thickness 


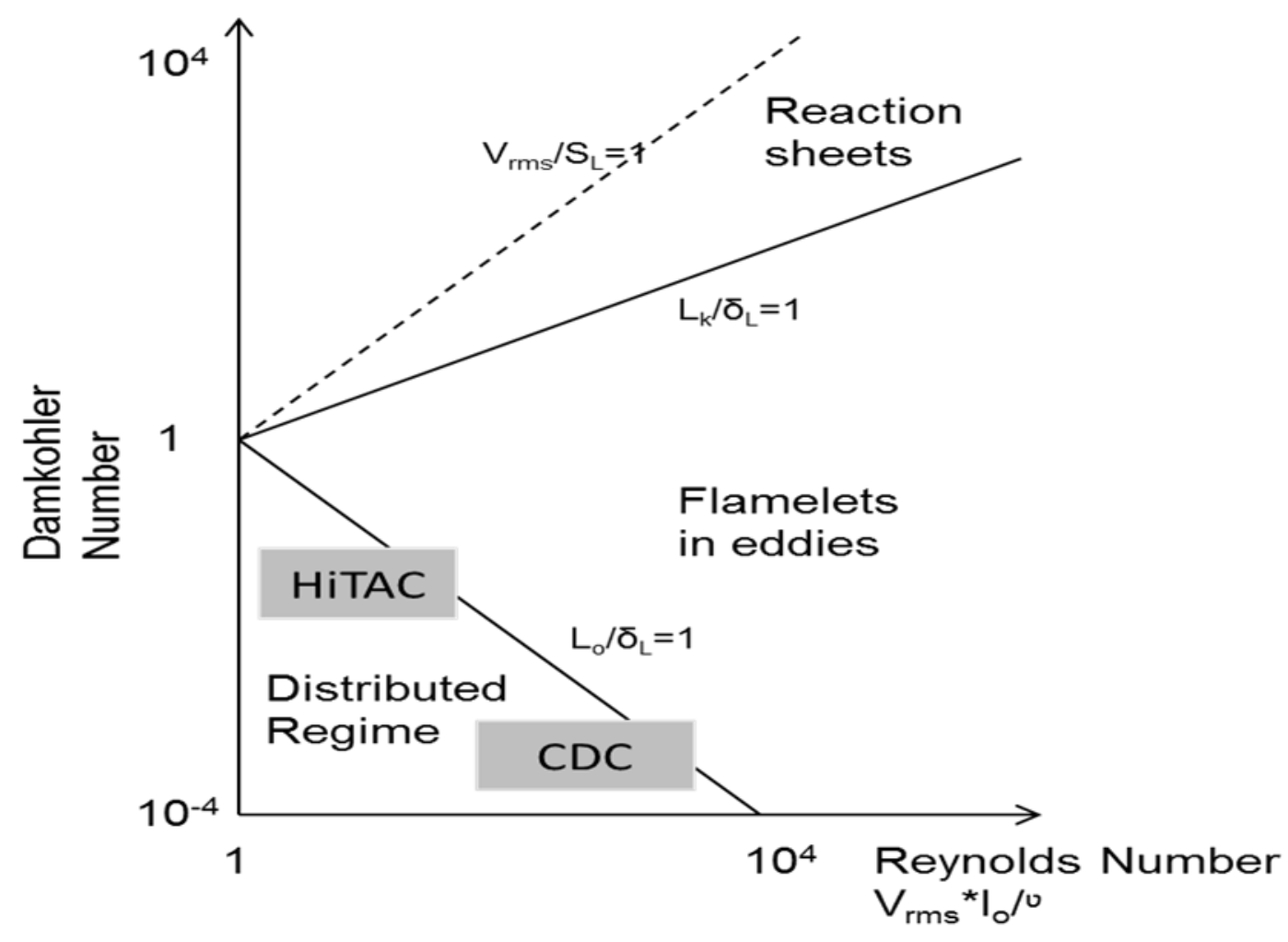

Figure 1. Combustion regimes with respect to Da and Re`. 


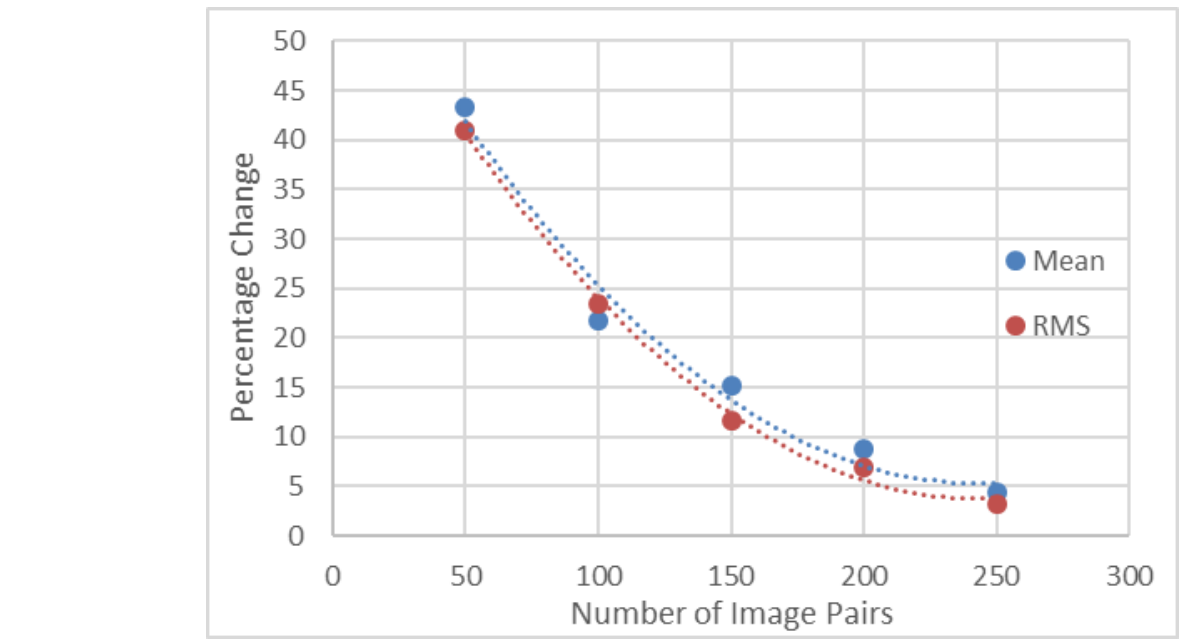

Figure 2. Percentage change in mean and fluctuating velocities vs. number of image pairs.

Figure 2

2

(2)




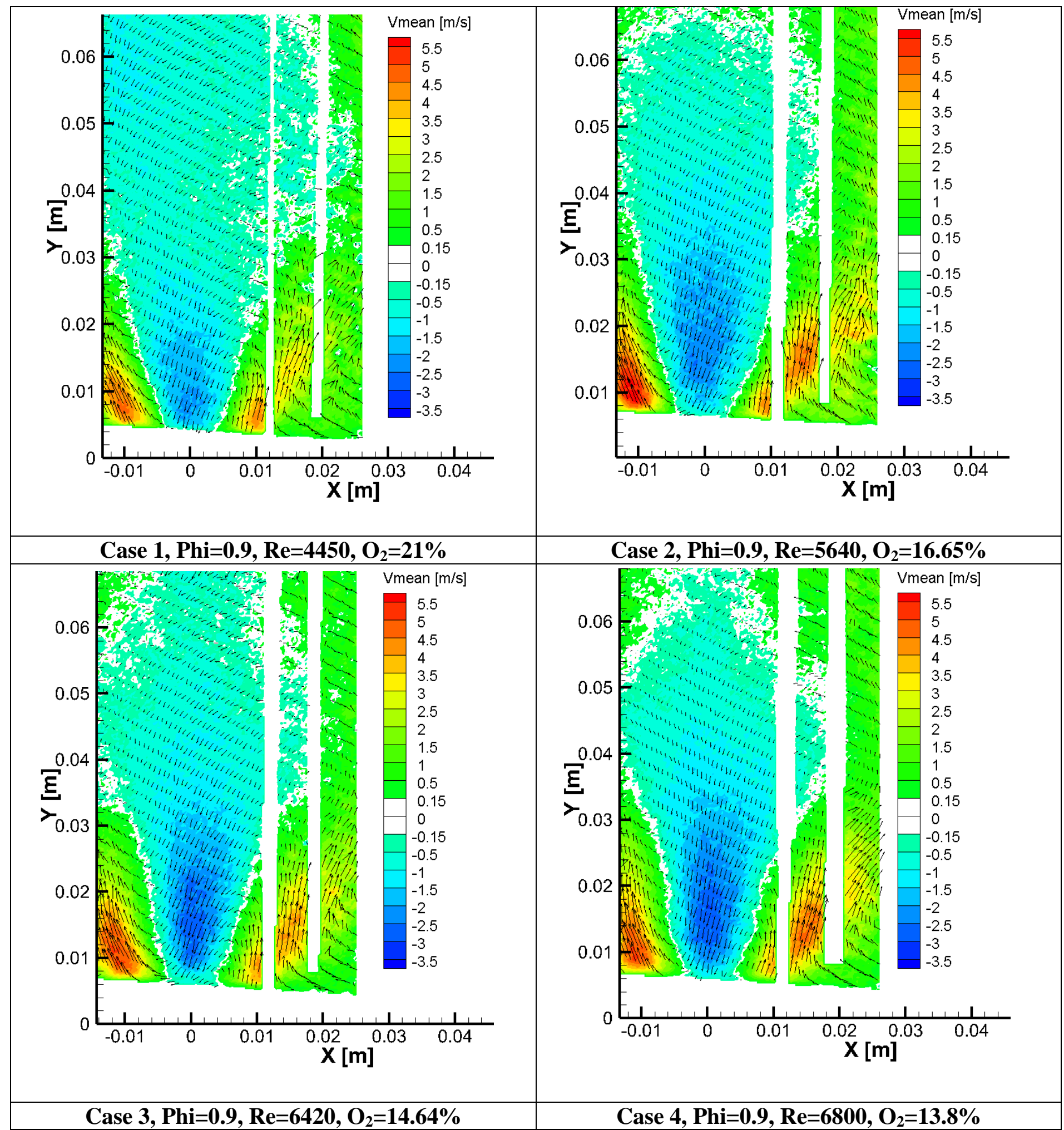

Figure 4. Velocity flow field for cases 1-4 with focus on velocity vectors. [For illustration, recirculation zone is outlined by white band] 


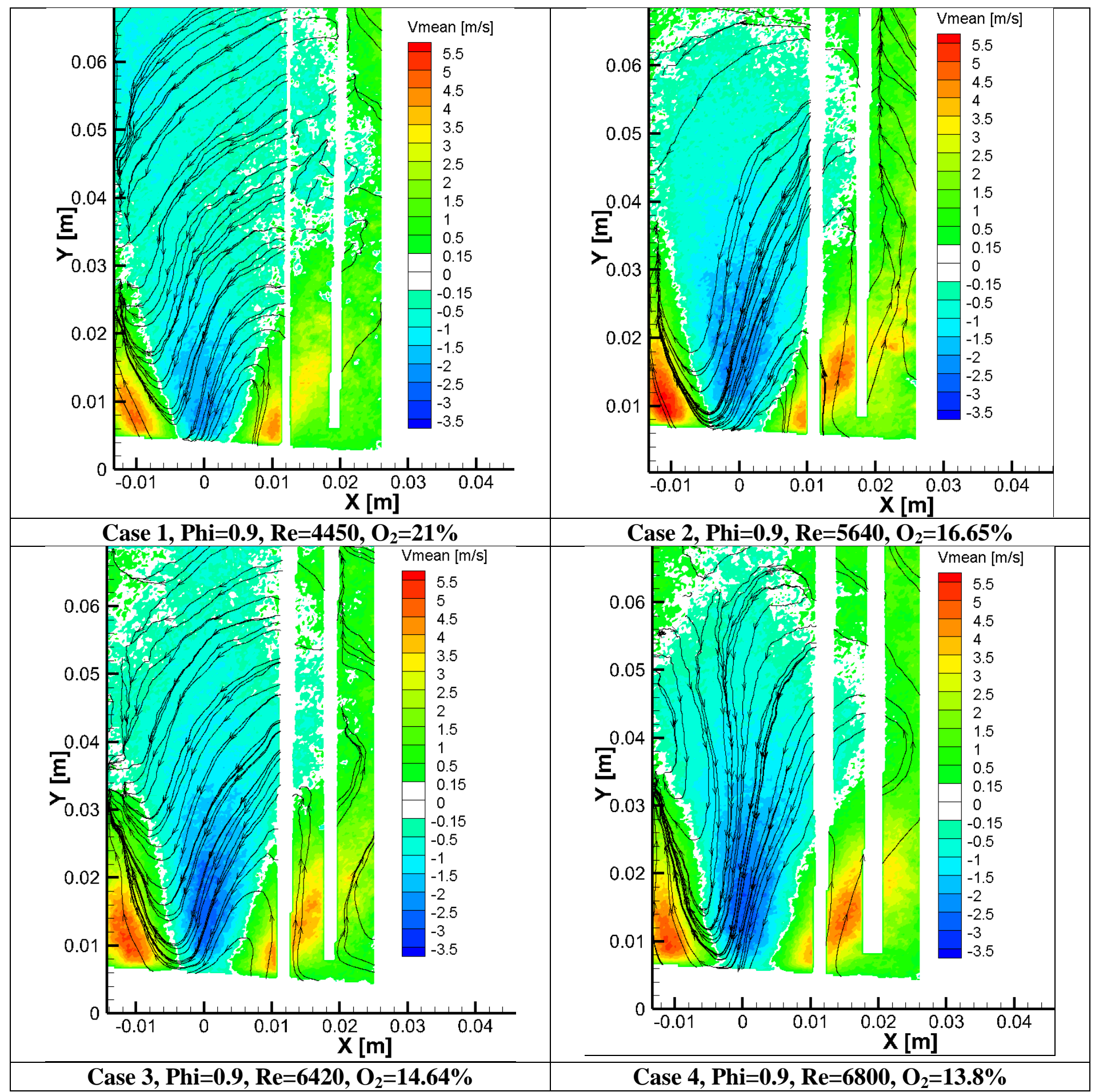

Figure 5. Velocity flow field for cases 1-4 with focus on streamlines trace. [For illustration, recirculation zone is outlined by white band] 


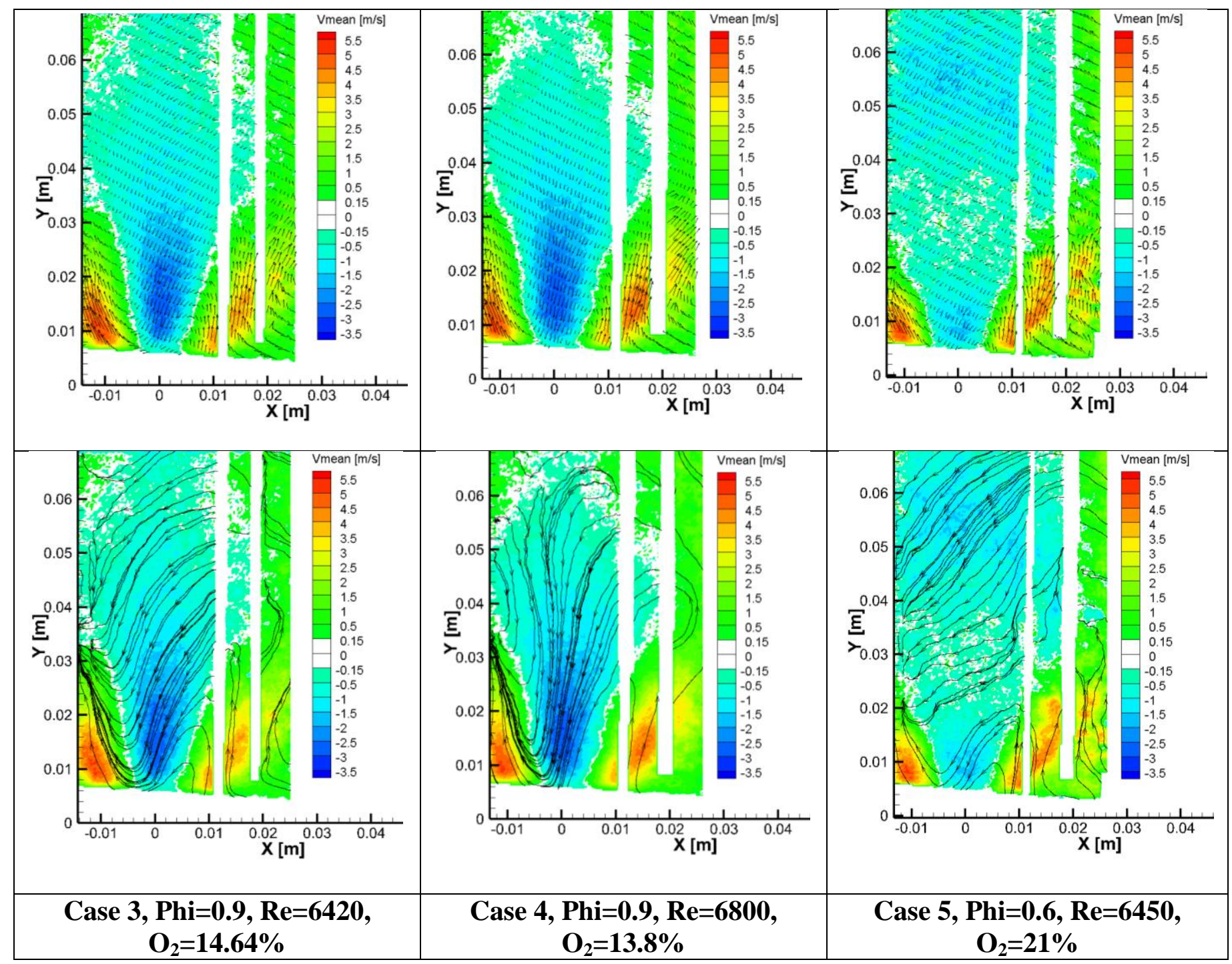

Figure 6. Velocity flow field for cases 3-5 with focus on velocity vectors (top) and streamline traces (bottom). [For illustration, recirculation zone is outlined by white band] 


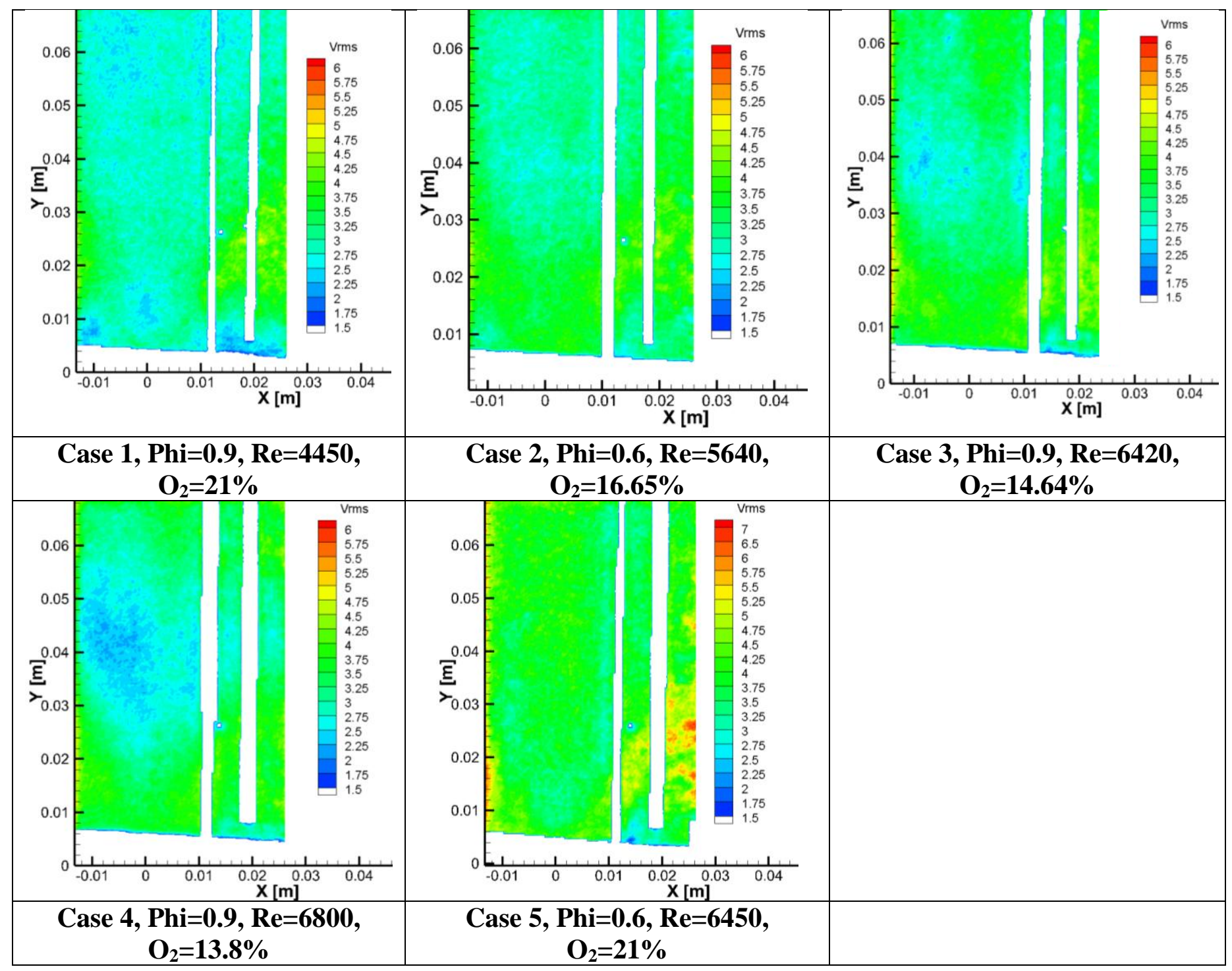

Figure 7. Velocity fluctuations $\left(V_{\text {rms }}\right)$ in $\mathrm{m} / \mathrm{s}$ for the different cases examined. 
Figure 8

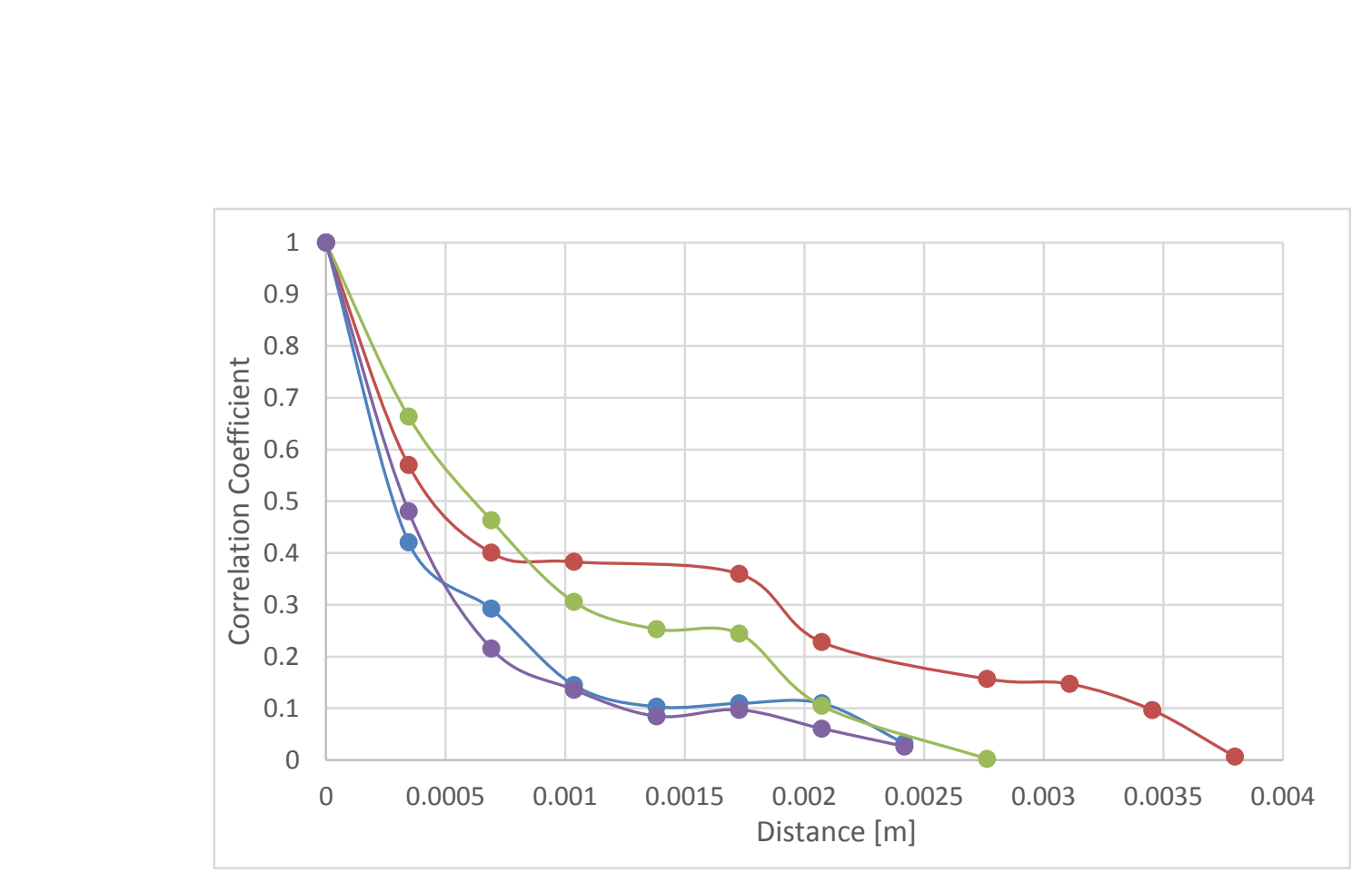

Figure 8. Sample data for correlation coefficient vs. distance.

(a)

\section{8} $\sqrt{2}$

\section{Figure 8}

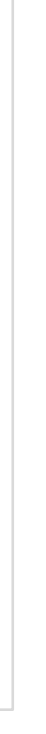

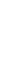
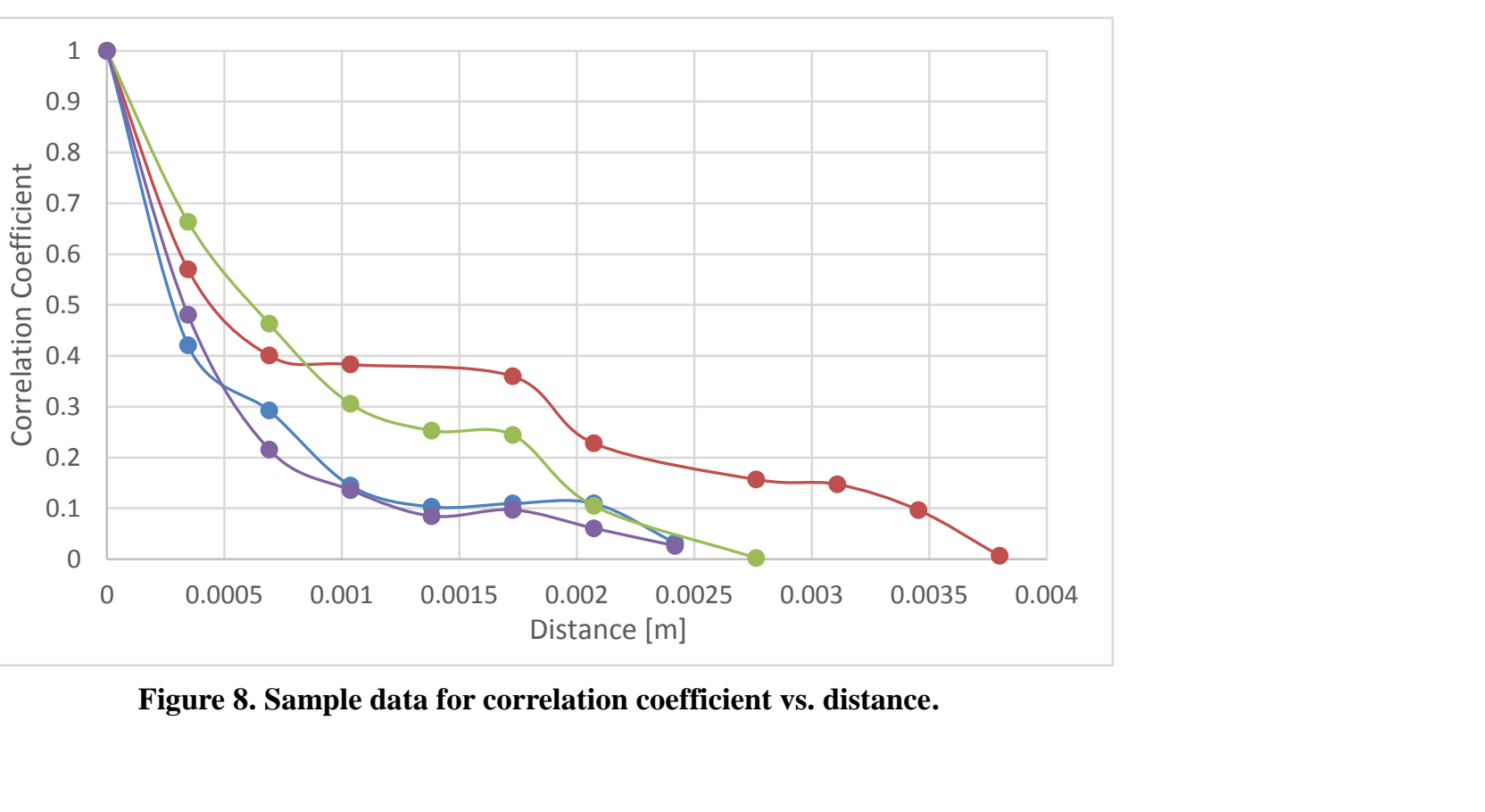


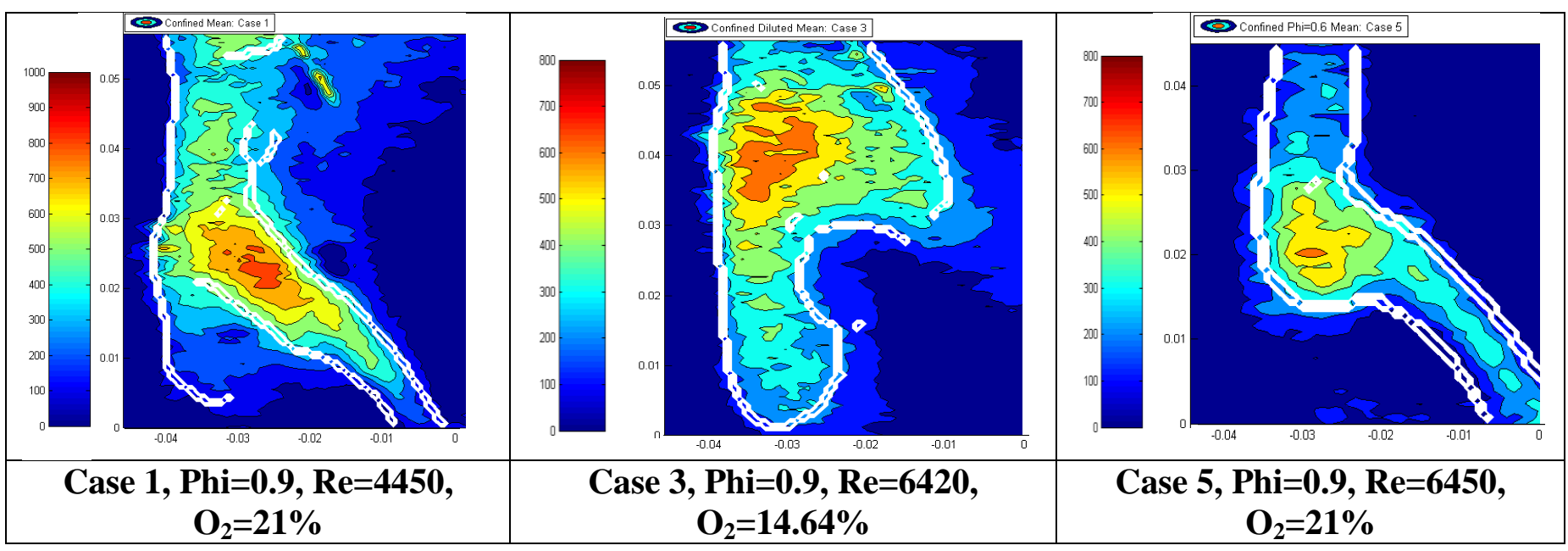

Figure 9. OH-PLIF signal with flame boundary detection. 


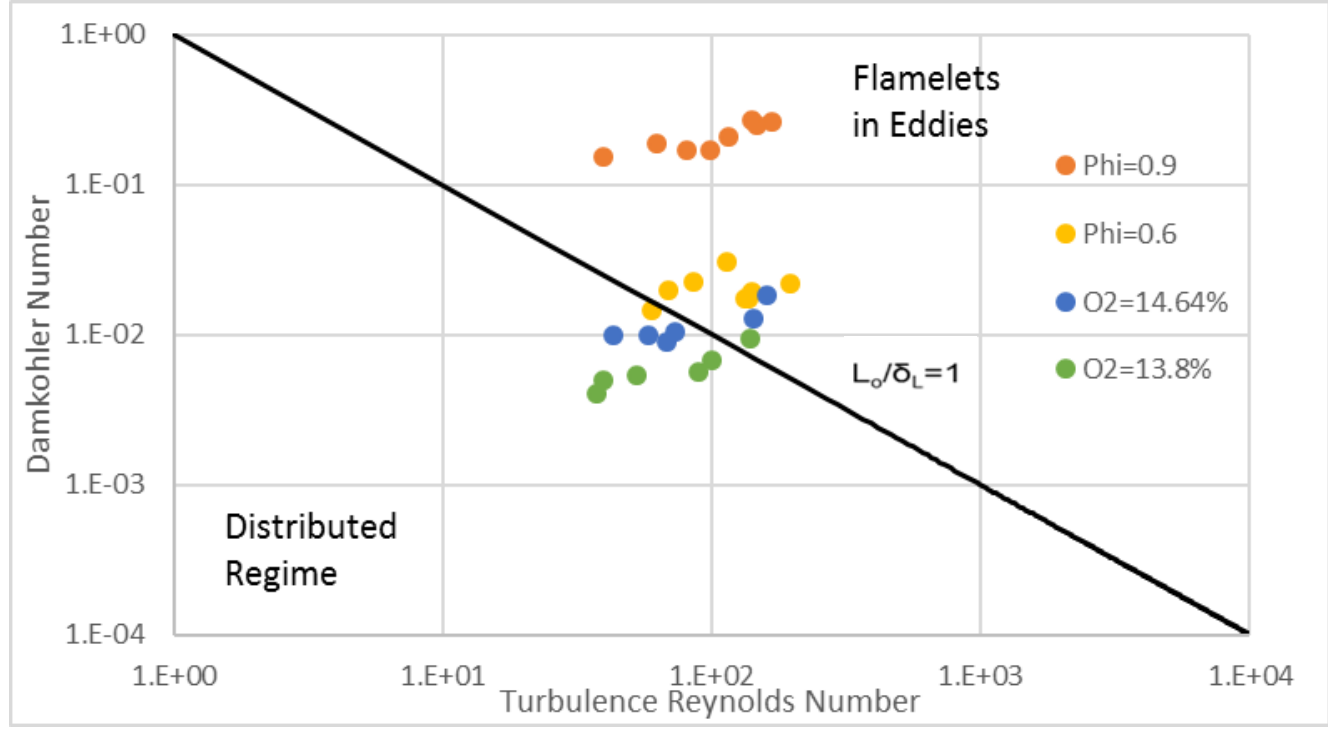

Figure 10. Combustion regimes for cases 1, 3, 4, and 5 at the different flame boundary locations examined. 


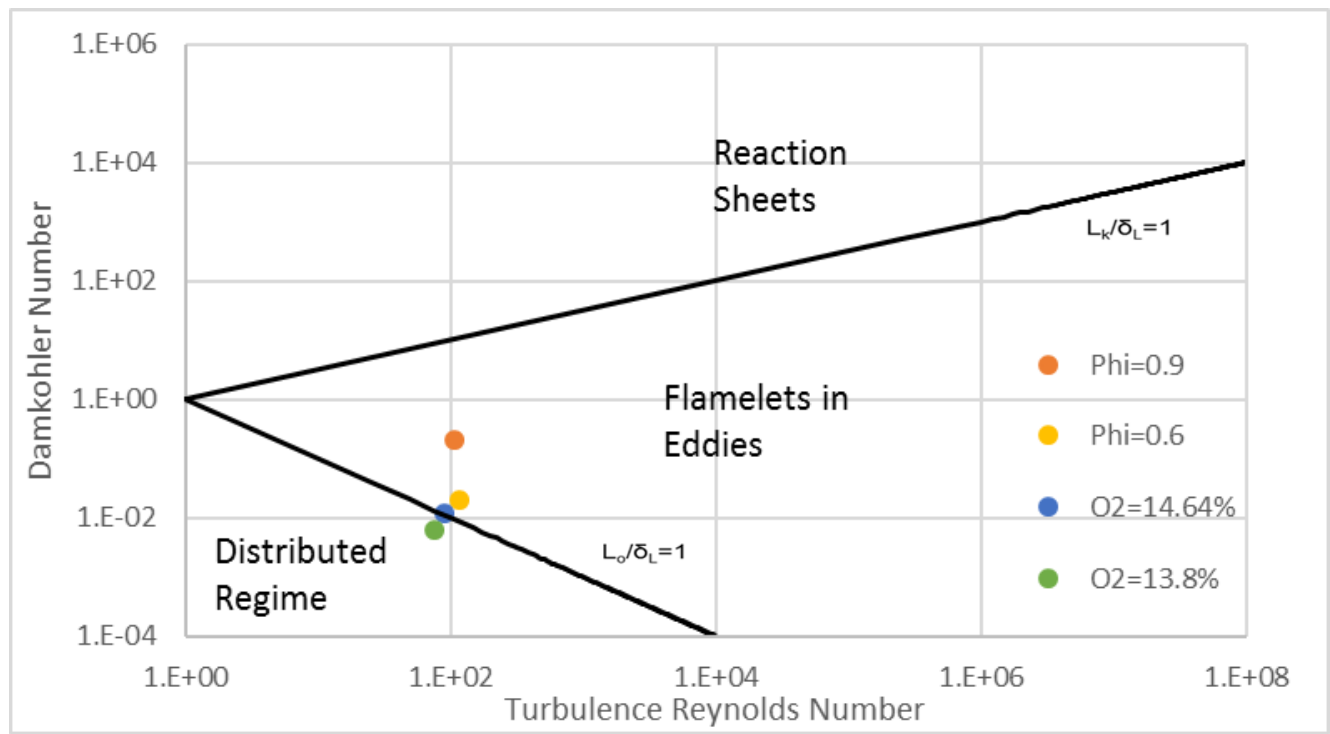

Figure 11. Combustion Regimes for cases 1, 3, 4, and 5. 


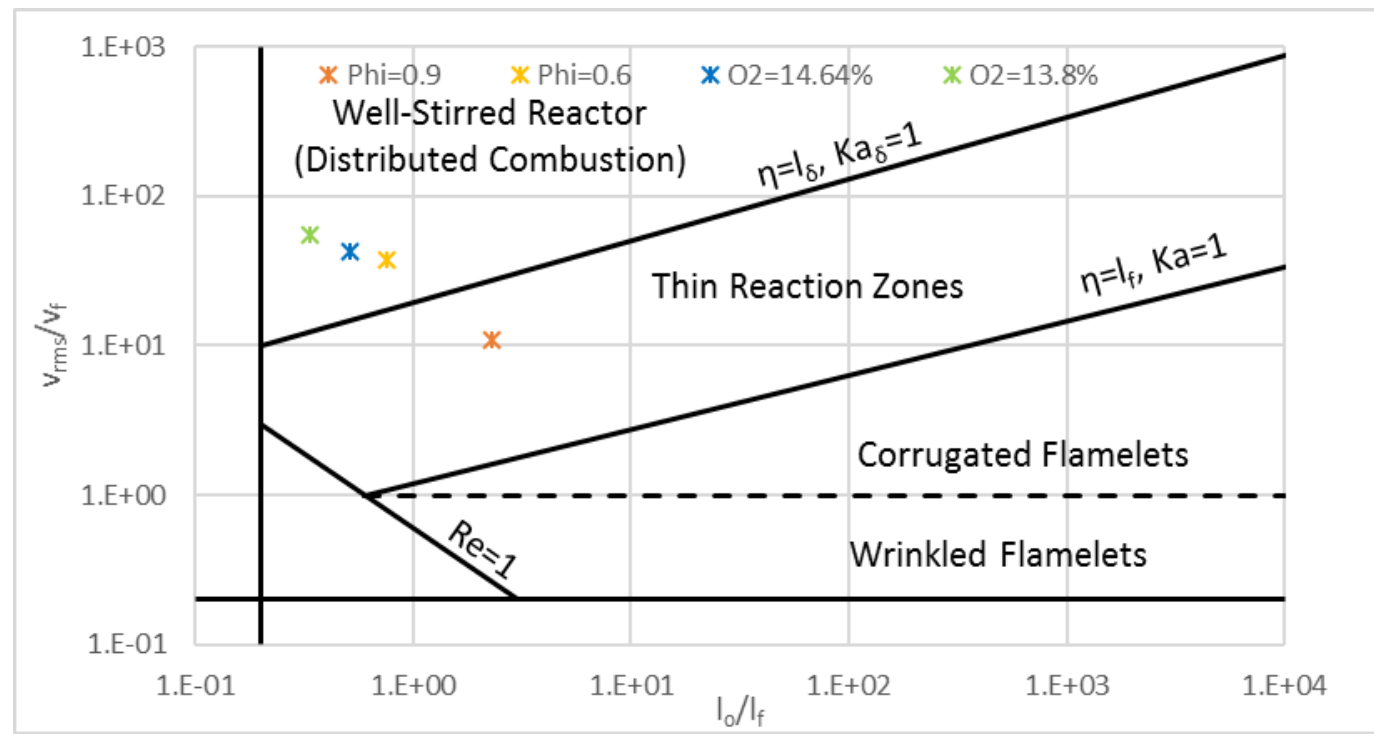

Figure 12. Combustion Regimes for cases 1, 3, 4, and 5. 